\section{Worker Policing}

Tom Wenseleers, Cintia Akemi Oi and

Ricardo Caliari Oliveira

Department of Biology, Laboratory of

Socioecology and Social Evolution, KU Leuven, Leuven, Belgium

Ants, bees, and wasp colonies display a remarkable reproductive division of labor, whereby one or several queens carry out most of the reproduction and the daughter workers normally specialize in nonreproductive tasks, such as foraging, defending the nest, and engaging in brood care. At the surface, this makes social insect colonies resemble perfectly harmonious $>$ superorganisms where all individuals work towards increasing the survival and the reproduction of the colony as a whole. This view has been challenged by the realization that, unlike the cells of individual organisms, the workers in a social insect colony are not all clones of each other. Although the genetic interests of the various nestmates in a social insect colony are closely aligned, they are not identical. Research has shown, for example, that genetic asymmetries within the colony can cause the queens and workers to be in conflict over who reproduces as well as over the sex ratio of the colony's offspring (see entry " $>$ Conflicts of Interest Within Colonies"). In this chapter we will show how this sets the stage for queenworker conflicts over male parentage and how such conflict can be resolved via social coercion, otherwise known as "policing" mechanisms.

\section{Conflict over Male Parentage}

In most eusocial Hymenoptera, the workers have lost the capability to mate, so that they have no possibility of having daughters. Nevertheless, workers are not always completely sterile; as in many species, they can activate their ovaries and lay unfertilized eggs [20], which - owing to - haplodiploidy - can give rise to viable, asexually produced males. Since both queens and workers are genetically most related to their own sons (life-for-life relatedness $r=1 / 2$ ), $>$ inclusive fitness theory predicts significant queen-worker and worker-worker conflict over male parentage [6]. Worker reproduction can have significant costs because reproductive workers usually perform little or no useful work in the colony [22].

\section{Policing of Male Production by Workers}

Research has shown that various forms of social coercion can prevent workers from successfully reproducing and that this can limit the expression of costly conflict $[6,15]$. First, in species with small colonies, where the queen can easily patrol the whole nest, she can stop the workers from reproducing by aggressing reproductive workers or by eating the eggs they lay. In 1978, the term 
"queen policing" was coined for this behavior, and empirical studies have shown such centralized control to be common in small-colony polistine and $>$ vespine wasps, halictid bees, $\checkmark$ bumble bees, and some ant species [11, 20]. Second, based on kinship arguments, it was later proposed that nonreproductive workers could also be selected to prevent "outlaw" workers from reproducing [15-17]. In analogy to queen policing, such decentralized, mutual inhibition of worker reproduction by other workers was referred to as "worker policing" [13, 15], and in 1989, Ratnieks and Visscher first documented its existence in the western honey bee, Apis mellifera, by showing that workers selectively destroy eggs laid by other workers [14]. Since then, worker policing has been recorded in about 30 species of social Hymenoptera, including several other species of honey bees, large-colony vespine wasps (e.g., in yellowjackets Vespula vulgaris and $V$. germanica and the hornet Vespa crabro), and some ants (e.g., in Acromyrmex - leafcutter ants and Camponotus carpenter ants) [20]. As these species comprise different lineages that independently evolved sociality, it is clear that worker policing has convergently evolved independently many times [20]. In contrast to queen policing, worker policing can also be very effective in species with very large colonies containing many thousands of workers [15].

\section{The Selective Basis of Worker Policing}

What factors cause worker policing to be selected for? The original hypothesis, first proposed by Starr [17] and Seeley [16] based on inclusive fitness arguments, was that worker policing would carry indirect genetic benefits in species where workers are collectively more related to the queen's sons than to other workers' sons [15]. Such a situation occurs in polyandrous species, in which the mother queen is mated to two or more males (Fig. 1) or when the colony is headed by several related queens [15]. This hypothesis was formalized and extended using population genetic models by Woyciechowski and Łomnicki [24] and Ratnieks [13]. Later,
Ratnieks and Visscher corroborated this hypothesis by showing that in the honey bee, where queens mate with multiple (about ten) males, workers indeed kill or police each other's eggs [14]. In further support of the relatedness theory for the evolution of worker policing, a review of observational evidence for policing in 48 hymenopteran species [20] found that, as predicted, worker policing occurs more frequently in species in which workers are more related to the queen's sons (e.g., three species of honey bees, the German wasp Vespula germanica, Pachycondyla ants, and Acromyrmex leafcutter ants, which are all polyandrous, and the multiple-queen ant Formica fusca), while the reverse trend is seen for queen policing (Fig. 2a). Further support for the role of relatedness came from the review of male parentage data in 90 species of Hymenoptera, which demonstrated that the percentage of adult males that were workers' sons was about 100 times lower in species where workers were more related to the queen's sons than in species where they were more related to the sons of other workers, presumably due to the presence of highly effective worker policing (Fig. 2b) [20].

Both empirical evidence and theoretical work, however, have shown that there are several other factors that can select for policing besides kinship differences to males $[6,15,20]$. This can explain why worker policing also appears to occur in species where workers are more closely related to the sons of other workers than to sons of the queen, e.g., in the monandrous ant Camponotus floridanus and the hornet Vespa crabro, where queens are usually singly mated [20]. In fact, worker policing even occurs in species with clonal colonies, such as in the obligatory asexually reproducing ponerine ant $>$ Platythyrea punctata [5] and the clonal raider ant Ooceraea biroi [18], where kinship benefits of policing are absent. In these cases, worker policing is more akin to the immune surveillance of cancer cells in genetically homogeneous multicellular organisms in the sense that worker policing presumably helps to maintain colony efficiency via the control of individuals that do not respond properly to regulatory 

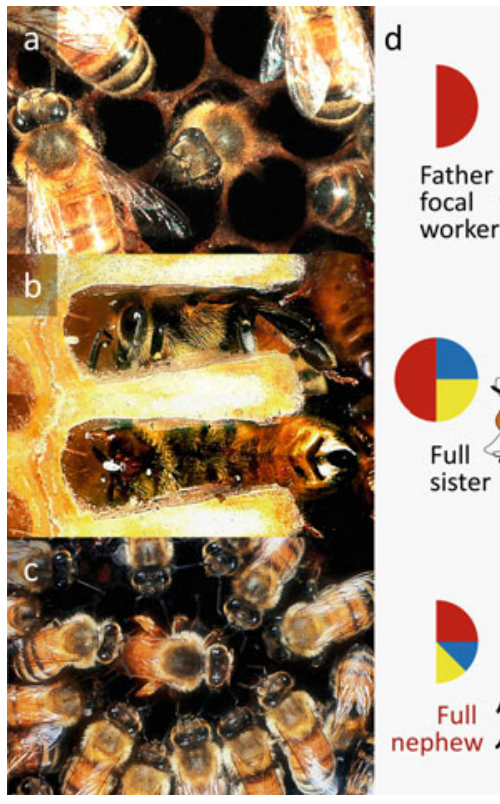

Worker Policing, Fig. 1 Worker policing in the honey bee and its selective basis. (a) A small number of workers reproduce even in the presence of the queen. (Photo by Benjamin P. Oldroyd). (b) Worker-laid eggs, however, are selectively eaten or "policed" by other workers [14]. (Photo by Francis L.W. Ratnieks). (c) Worker policing allows the queen to retain her reproductive monopoly in the colony. (Photo by Francis L.W. Ratnieks). (d) In the honey bee, worker policing is selected for because queen polyandry in combination with the haplodiploid sex-

signals and so compromise the functioning of the colony unit [18].

Theoretical models have confirmed that worker policing can indeed readily be selected for in the absence of any relatedness advantage if there are colony productivity benefits $[13,20]$. Empirically, colony productivity benefits could occur if policing occurs via targeted aggression of workers with developed ovaries, as this could act as a punishment mechanism and favor workers to work rather than engage in reproduction, resulting in an immediate productivity benefit for the colony $[6,15]$. If policing occurs via egg eating, productivity benefits would occur only if worker-laid eggs had low viability or if policing directly deterred workers from reproducing, but there is as yet no conclusive evidence for either scenario [6]. Nevertheless, the costs of worker reproduction are well documented, with many determining system causes workers to be more closely related to the queen's sons (their own brothers, life-forlife relatedness $r=1 / 4$ ) than to the sons of other workers (a mix of full nephews and half-nephews, life-for-life relatedness $r=3 / 8$ and $r=1 / 8$ ) [13]. Under $>$ haplodiploidy, females are diploid and develop from fertilized eggs, while males are typically haploid and develop asexually from unfertilized eggs. Pie charts represent the share of the genome derived from the different parents (the diploid mother queen or one of several haploid fathers)

studies showing that reproductive workers work less than nonreproductive ones [22]. In addition, in $>$ stingless bees - where the colony kinship structure is invariable and colonies are always headed by a single-mated queen - variation in worker male parentage has been shown to be linked to variation in the cost of worker reproduction [23]. In particular, workers in the genus Melipona were shown to reproduce only in those species in which the queen lays a high proportion of female eggs; in that case workers can afford to replace some worker-destined female eggs by male worker-laid eggs without compromising the long-term maintenance of the colony's workforce [23].

In addition to the kinship and productivity benefits of policing, three other factors have been suggested to favor worker policing $[6,20]$. First, models show that worker policing could be 


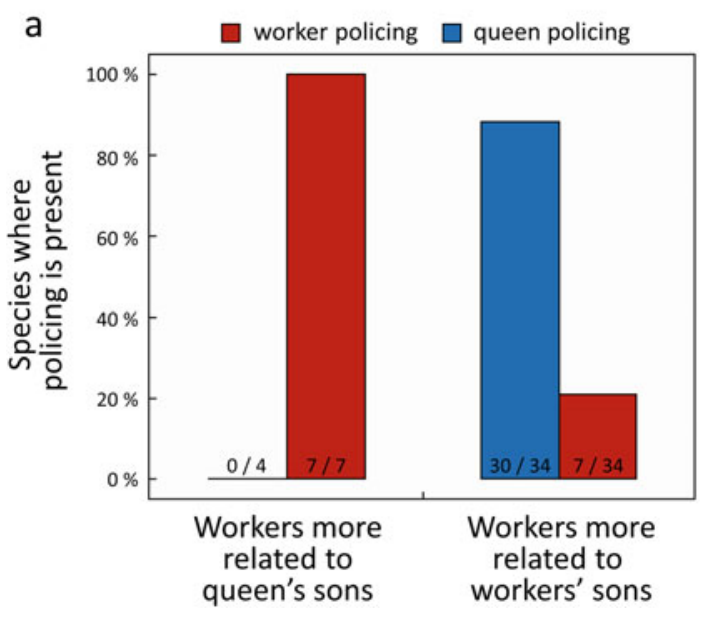

Worker Policing, Fig. 2 Support for the role of relatedness in the evolution of worker policing. (a) Across 48 species of ants, bees, and wasps, worker policing (red bars) occurs in all species (7/7) in which workers are more related to the queen's sons but only in $21 \%$ of the species (7/34) where workers are more closely related to workers' sons. For queen policing (blue bars), the reverse trend is

selected for as a mechanism for the workers to attain a more female-biased sex ratio and allow them to capitalize on the production of highly related full-sister queens [23]. Second, in the - Cape honey bee and bumble bees, where workers often parasitize and lay eggs in genetically unrelated colonies, it has been suggested that worker policing could be a side-effect of selection for the removal of eggs laid by unrelated worker parasites $[1,25]$. Third, empirical data shows that in some species, worker policing is carried out for purely selfish reasons $[2,20,25]$. That is, in situations where the policing individuals themselves lay eggs, they can increase their direct reproduction through policing. Such selfish or "corrupt" worker policing occurs in several small-colony vespine and polistine wasps, as well as in some bumble bees, stingless bees, and ants (e.g., in Aphaenogaster and $>$ Temnothorax) [1]. In these cases, selfish policing does not result in reproductive workers aggressing the queen or in significant cannibalism of queen-laid eggs. This is presumably caused by the fact that the cost of conflict would become too large if workers also hindered the queen's ability to produce offspring. Possible selfish motives of worker policing have been

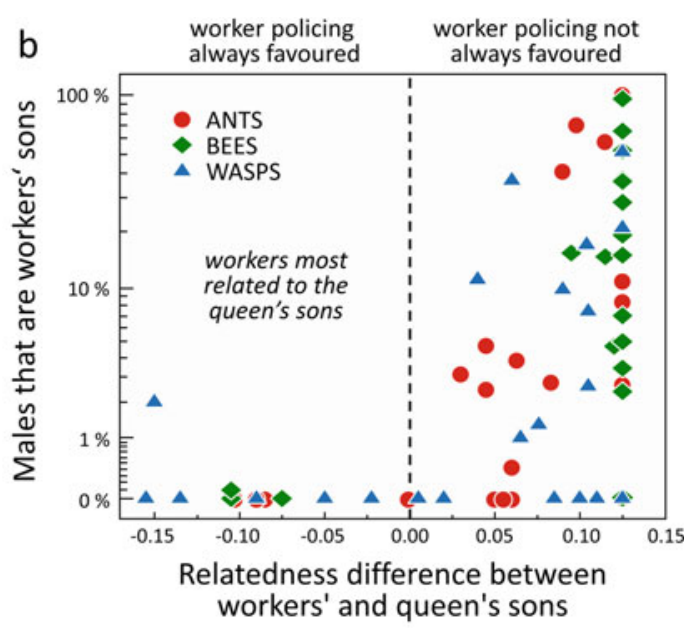

seen. (b) Across 90 species of ants (circles), bees (squares), and wasps (triangles), the mean percentage of adult males that are workers' sons is 100 times lower in species in which the workers are more related to the queen's sons $(0.14 \%$, area to the left of the dashed line) than in species in which the workers are more related to the sons of other workers (14\%). (Based on data from Ref. [23])

excluded in the polyandrous ant Pachycondyla inversa and in the polyandrous common wasp Vespula vulgaris, as policing workers there did not have developed ovaries [20]. In the western honey bee Apis mellifera, it is also unlikely that reproductive workers significantly contribute to the policing of worker-laid eggs, as very few $(0.1 \%)$ of the workers attempt to reproduce in the presence of the queen [21], while many more (1\%) engage in worker policing [4]. Data have also shown clear patriline specialization in carrying out policing behavior, supporting that the trait has a genetically heritable basis and that policing is carried out by workers belonging to diverse age cohorts [4].

\section{The Effect of Kinship and Policing on Worker Selfishness}

If workers can choose either altruistically to give up all reproduction and work for the benefit of the colony or selfishly to engage in direct reproduction, what equilibrium strategy would natural selection favor? Such an equilibrium is known as the evolutionarily stable strategy or ESS, and both 


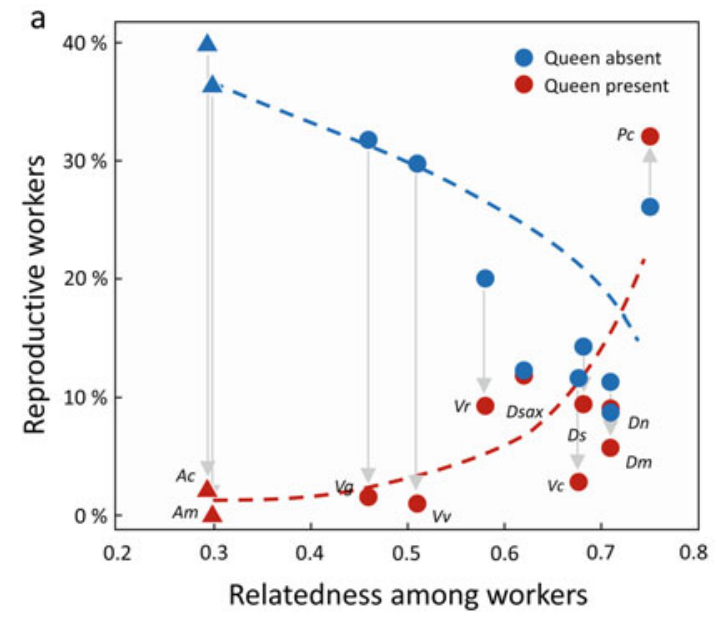

Worker Policing, Fig. 3 Effects of relatedness and policing on attempted worker reproduction in nine species of wasps (circles) and two species of honey bees (triangles). (a) In queenless colonies (blue symbols), worker selfishness is limited purely by relatedness [22], and fewer workers activate their ovaries in species with higher worker-worker relatedness. In queenright colonies (red symbols), by contrast, workers behave less selfishly in species with low worker-worker relatedness. This counterintuitive result is caused by the fact that policing is selected for more strongly in species with low relatedness and that

theory and empirical data have shown that policing as well as kinship can affect the ESS level of worker selfishness, measured by the proportion of workers that attempt to activate their ovaries and reproduce $[15,21,22]$. In the absence of the queen, theoretical predictions follow Hamilton's rule, and worker selfishness should be limited purely by relatedness $[15,22]$. In support of this prediction, comparative data from nine species of wasps and two species of honey bees $[7,9,21]$ show that in queenless colonies, fewer workers selfishly activate their ovaries in species with higher worker-worker relatedness (blue symbols in Fig. 3a). In the presence of the queen, however, workers should be selected to behave less selfishly in species with low worker-worker relatedness, as low relatedness selects more strongly for worker policing (Fig. 1d), and more effective policing disincentivizes worker reproduction [22]. That is, workers are better off not even trying to reproduce if nearly all the eggs they lay will be eaten anyway $[15,22]$. Comparative data on attempted worker reproduction in queenright colonies of

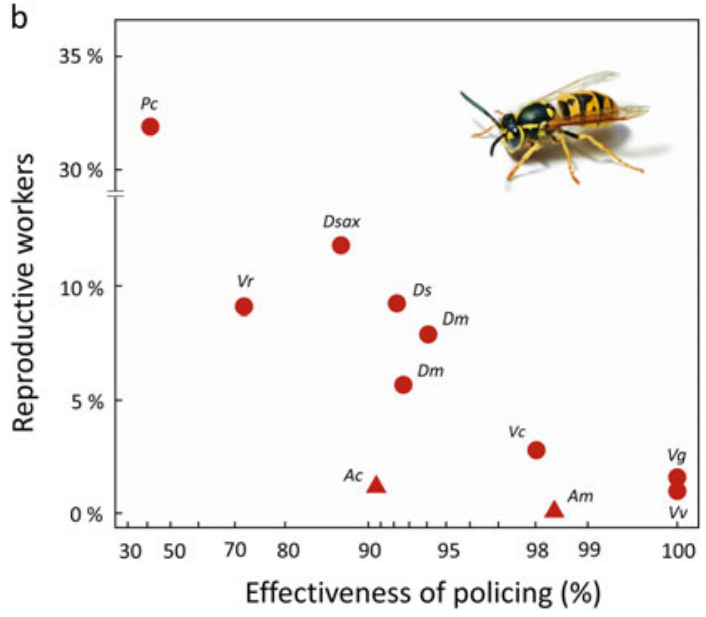

more effective policing reduces the incentive for workers to attempt to reproduce [9]. (b) In line with this hypothesis, fewer workers try to reproduce by activating their ovaries when the eggs they lay are more effectively policed [21]. Species abbreviations: Ac, Apis cerana; Am, A. mellifera; Dm, Dolichovespula media; Dn, D. norwegica; Dsax, D. saxonica; Ds, D. sylvestris; Pc, Polistes chinensis; Vc, Vespa crabro; Vg, Vespula germanica; $V r, V$. rufa; Vv, V. vulgaris. (Data from Refs. [7, 9, 19])

the same set of 11 species supports this prediction $[7,9,21]$. In species with low relatedness, fewer workers attempt to reproduce in the presence of the queen (red symbols in Fig. 3a), and attempted worker reproduction is negatively related to how effectively worker-laid eggs are policed by nestmates (Fig. 3b).

Hence, over many generations, policing of worker-laid eggs by the queen or workers selects for far fewer workers even trying to reproduce $[15,22]$. This implies that worker altruism is partly socially enforced $[15,21]$. Policing of attempted worker reproduction could also have a direct, immediate response on attempted worker reproduction. In particular, a direct deterrent effect is likely in those species where workers with active ovaries are attacked by nestmates, as this could presumably act as a punishment mechanism and cause aggressed workers to regress their ovaries $[6,15,20]$. In honey bees as well as in several ants and wasps, policing via egg cannibalism appears to co-occur with policing via targeted aggression of workers with activated 
ovaries [20]. The actual extent to which such policing deters workers from reproducing, however, remains to be measured.

\section{The Recognition of Egg Maternity and Cheater Workers}

The fact that worker-laid eggs are selectively policed in many social insect species implies the presence of mechanisms that enable the policing individuals to accurately discriminate between worker-laid and queen-laid eggs. The recognition of egg maternity is linked to subtle differences in the chemical profile of queen-laid and worker-laid eggs. For example, in the common wasp Vespula vulgaris a methyl-branched hydrocarbon 3-methyl nonacosane - was found to be more abundant on queen-laid eggs than on worker-laid eggs, and experimental application of this hydrocarbon onto worker-laid eggs was shown to reduce the probability of such eggs being policed [10]. This indicates that this compound is used as a queen egg-marking pheromone and is applied by the queen onto her eggs to signal that they should not be policed [10]. Interestingly, the same compound was described as abundant on the queen's cuticle and appeared to directly suppress the workers' ovary development [19]. Similarly, in the Florida carpenter ant Camponotus floridanus, experiments have shown that queen-characteristic hydrocarbons deposited onto the queen's eggs serve both as queen signals that directly suppress worker reproduction and serve as egg-marking pheromones that allow the workers to selectively police worker-laid eggs [3]. In cases where policing of reproductive workers occurs via aggression, recognition of reproductive status also appears to occur based on the perception of fertility-linked cues on the workers' cuticle. For example, in the ant Aphaenogaster cockerelli, the linear alkane pentacosane is more abundant on the cuticle of reproductive "cheater" workers, and experimental application of this hydrocarbon onto the cuticle of nonreproductive workers causes such workers to be aggressed [19]. Although in this case workers would benefit from disguising their fertility status, it is possible that the fertility-linked hydrocarbons are produced as an unavoidable by-product of their reproductive physiology so that reproductive workers would be unable to suppress their production [6]. Indeed, comparative studies show that queen pheromones and fertility signals are highly conserved across different independently evolved lineages of social insects [19]. This implies that such pheromones may be derived from ancestral fertility cues in solitary species, where ovary activation also leads to distinct changes in cuticular hydrocarbon profiles. Hence, such cues may be produced merely as by-products of reproductive physiology.

\section{Evasion of Policing}

Given that policing stops workers from reproducing, it might be expected that individual reproductive workers or workers belonging to individual patrilines could benefit if they could evade policing and rear their own sons $(r=1 / 2)$ or full-sisters' sons $(r=3 / 8)[1,6,15]$. For example, it is predicted that workers could benefit from mimicking the queen's signals $[1,6,15]$. Evidence supports the idea that honey bee workers can indeed cheat by mimicking one or several queen pheromone compounds and so evade policing $[1,12]$. For example, some rare lineages of anarchistic honey bee workers can reproduce in the presence of the queen by upregulating the levels of the queen pheromone 9-HDA in their mandibular glands and laying eggs with high levels of queenlike Dufour's gland esters, which presumably helps them and their eggs to avoid being policed [1, 12]. Worker mimicry of queen Dufour's gland esters and production of queenlike mandibular gland and tergal gland pheromones was also reported in the clonally reproducing Cape honey bee, Apis mellifera capensis. This mimicry causes workers to be mistaken for queens and treated accordingly, helping them to infiltrate and parasitize colonies of the conspecific - African honey bee Apis mellifera scutellata $[1,12]$. Recent evidence shows that these queen- 
characteristic Dufour's gland esters and tergal gland esters also double up as queen pheromones and directly suppress the reproduction of workers [12], even though the inhibitory effect was slightly less than that of the main queen mandibular gland queen pheromones, 9-ODA and 9-HDA. Workers of the Asian honey bees - Apis florea and $>A$. cerana have also been suggested to evade policing by a form of parasitism, in which they lay eggs in unrelated queenless colonies in which worker policing has been switched off so that the colony can rear a last batch of males [1]. Furthermore, in the annual colonies of bumble bees and some vespine wasps, workers even go to the extreme measure of killing their own mother queen to evade queen policing and be able to reproduce without interference $[8,15,25]$. In one vespine wasp species, such worker matricide was found to be facultatively expressed and was observed to occur only in colonies where the queen was mated with a single male, which was expected by theory, as workers there were collectively more closely related to other workers' sons than to the queen's sons, their brothers [8].

\section{Policing of Other Types of Selfish Behavior}

Although policing in insect societies has mainly been discussed as a mechanism to resolve queenworker conflict over male parentage, similar forms of social coercion also mediate conflict over caste fate and conflict over breeder replacement in species where all females are totipotent and capable of mating $[6,15]$. These forms of policing are covered in the entry "Conflicts of Interest Within Colonies".

\section{Cross-References}

\author{
$\checkmark$ Carpenter Ants \\ - Conflicts of Interest Within Colonies \\ $\checkmark$ Leafcutter Ants \\ - Temnothorax
}

\section{References}

1. Beekman, M., \& Oldroyd, B. P. (2008). When workers disunite: Intraspecific parasitism by eusocial bees. Annual Review of Entomology, 53, 19-37.

2. Bonckaert, W., Tofilski, A., Nascimento, F. S., Billen, J., Ratnieks, F. L. W., \& Wenseleers, T. (2011). Co-occurrence of three types of egg-policing in the Norwegian wasp Dolichovespula norwegica. Behavioral Ecology and Sociobiology, 65, 633-640.

3. Endler, A., Liebig, J., Schmitt, T., Parker, J. E., Jones, G. R., et al. (2004). Surface hydrocarbons of queen eggs regulate worker reproduction in a social insect. Proceedings of the National Academy of Sciences of the United States of America, 101, 2945-2950.

4. Ernst, U. R., Cardoen, D., Cornette, V., Ratnieks, F. L. W., de Graaf, D. C., et al. (2017). Individual and genetic task specialization in policing behaviour in the European honeybee. Animal Behaviour, 128, 95-102.

5. Hartmann, A., Wantia, J., Torres, J. A., \& Heinze, J. (2003). Worker policing without genetic conflicts in a clonal ant. Proceedings of the National Academy of Sciences of the United States of America, 100, 12836-12840.

6. Helanterä, H., \& Ratnieks, F. L. W. (2018). Worker conflict and worker policing. In M. D. Breed \& J. Moore (Eds.), Encyclopedia of animal behavior (Vol. 4, pp. 621-628). Amsterdam: Academic.

7. Holmes, M. J., Tan, K., Wang, Z., Oldroyd, B. P., \& Beekman, M. (2014). Why acquiesce? Worker reproductive parasitism in the Eastern honeybee (Apis cerana). Journal of Evolutionary Biology, 27, 939-949.

8. Loope, K. J. (2015). Queen killing is linked to high worker-worker relatedness in a social wasp. Current Biology, 25, 2976-2979.

9. Nanork, P., Chapman, N. C., Wongsiri, S., Lim, J., Gloag, R. S., \& Oldroyd, B. P. (2007). Social parasitism by workers in queenless and queenright Apis cerana colonies. Molecular Ecology, 16, 1107-1114.

10. Oi, C. A., Van Oystaeyen, A., Oliveira, R. C., Millar, J. G., Verstrepen, K. J., et al. (2015). Dual effect of wasp queen pheromone in regulating insect sociality. Current Biology, 25, 1638-1640.

11. Oster, G. F., \& Wilson, E. O. (1978). Caste and ecology in the social insects. Princeton: Princeton University Press. 352 pp.

12. Princen, S. A., Oliveira, R. C., Ernst, U. R., Millar, J. G., van Zweden, J. S., \& Wenseleers, T. (2019). Honeybees possess a structurally diverse and functionally redundant set of queen pheromones. Proceedings of the Royal Society of London. Series B, Biological Sciences, 286, 20190517.

13. Ratnieks, F. L. W. (1988). Reproductive harmony via mutual policing by workers in eusocial Hymenoptera. American Naturalist, 132, 217-236. 
14. Ratnieks, F. L. W., \& Visscher, P. K. (1989). Worker policing in the honeybee. Nature, 342, 796-797.

15. Ratnieks, F. L. W., \& Wenseleers, T. (2008). Altruism in insect societies and beyond: Voluntary or enforced? Trends in Ecology \& Evolution, 23, 45-52.

16. Seeley, T. D. (1985). Honeybee ecology: A study of adaptation in social life. Princeton: Princeton University Press.

17. Starr, C. K. (1984). Sperm competition, kinship, and sociality in the aculeate Hymenoptera. In Sperm competition and the evolution of animal mating systems (Vol. 428, p. 459). New York: Academic Press.

18. Teseo, S., Kronauer, D. J. C., Jaisson, P., \& Chaline, N. (2013). Enforcement of reproductive synchrony via policing in a clonal ant. Current Biology, 23, 328-332.

19. Van Oystaeyen, A., Oliveira, R. C., Holman, L., van Zweden, J. S., Romero, C., et al. (2014). Conserved class of queen pheromones stops social insect workers from reproducing. Science, 343, 287-290.

20. Wenseleers, T., \& Ratnieks, F. L. W. (2006). Comparative analysis of worker reproduction and policing in eusocial Hymenoptera supports relatedness theory. American Naturalist, 168, E163-EE79.

21. Wenseleers, T., \& Ratnieks, F. L. W. (2006). Enforced altruism in insect societies. Nature, 444, 50.

22. Wenseleers, T., Helanterä, H., Hart, A., \& Ratnieks, F. L. W. (2004). Worker reproduction and policing in insect societies: An ESS analysis. Journal of Evolutionary Biology, 17, 1035-1047.

23. Wenseleers, T., Helanterä, H., Alves, D. A., DueñezGuzmán, E., \& Pamilo, P. (2013). Towards greater realism in inclusive fitness models: The case of worker reproduction in insect societies. Biology Letters, 9, 20130334.

24. Woyciechowski, M., \& Łomnicki, A. (1987). Multiple mating of queens and the sterility of workers among eusocial Hymenoptera. Journal of Theoretical Biology, 128, 317-327.

25. Zanette, L. R., Miller, S. D., Faria, C. M., Almond, E. J., Huggins, T. J., et al. (2012). Reproductive conflict in bumblebees and the evolution of worker policing. Evolution, 66, 3765-3777. 